\title{
Theatre as Representation (TAR) and the Teaching of a Graduate Administration of Inclusive Schools Course
}

\author{
Matthew J. Meyer and David C. Young \\ St. Francis Xavier University
}

\section{Author Note}

Correspondence regarding this article should be addressed to Matthew J. Meyer, Faculty of Education, St. Francis Xavier University, P.O. Box 5000, Antigonish, Nova Scotia, B2G 2W5. Tel: 902-867-5267, Fax: 902-867-3887. E-mail: mmeyer@stfx.ca or

David C. Young, Faculty of Education, St. Francis Xavier University, PO Box 5000, Antigonish, Nova Scotia, B2G 2W5. Tel: 902-867-2215, Fax: 902-867-3887. Email: dyoung@stfx.ca

\begin{abstract}
Based on continuing research in Theatre as Representation (TAR), this paper examines and explores an application of a TAR based dramatic scenario that expands each participant's creative awareness of both content and participation in an administration of inclusive schools graduate Master of Education (M.Ed.) course.
\end{abstract}

Keywords: inclusive education; administration; theatre as representation 


\section{Theatre as Representation (TAR) and the Teaching of a Graduate Administration of Inclusive Schools Course}

\section{Conceptual Framework and Theatre as Representation (TAR) Defined}

In an era of inclusion, coupled with an increasing number of governmental regulations, it may seem natural for educators' preparation programs to deliver knowledge in a traditional format (teacher-centered instruction). As well, research findings may not be as easily understandable to many in-service teachers who have not experienced either professional development or Bachelor of Education (B.Ed.) courses in inclusive education. Educational research findings remain somewhat esoteric unless conveyed in a manner that is meaningful to practitioners as well as scholars. Communicating research results to improve classroom instruction has been done through a variety of means from courses (B.Ed., M.Ed., etc.) to professional development workshops or conferences. Clearly, a specific audience's response and/or receptivity are a matter of individual interpretation. In order for the connections to be made between the theories behind the research and the practice as experienced by the practitioners/students, individuals need to be cognitively, affectively, and perhaps even physically involved in the direction of the ideas vis-à-vis their own practice. "The classroom situation most provocative of thoughtfulness and critical consciousness is the one in which teachers and learners find themselves conducting a kind of collaborative search, each from her or his lived situation” (Greene, 1995, p. 23).

Taking Greene's (1995) concept to heart within the context of teaching graduate level educational administration courses, we have to wonder how provocative our pedagogy is in stimulating collaborative interactions between students and instructors. Currently, with many politically and fiscally conservative-minded governments coming to power, much of the current legislation has skewed the field to what seems to be a more right-wing, rules-based approach to school governance. For preservice and in-service teachers, a basic knowledge of such administrative tasks as classroom management, liability for negligence, reporting responsibilities and due process in student academic and behavioral assessment(s) has become necessary. The following account of theatre as representation (TAR) depicts a successful blueprint for such a provocative pedagogy. One of the foundational elements of TAR pedagogy is the use of visual and/or performing arts.

Art, in its form unites the very same relation of doing and undergoing, outgoing and incoming energy, but makes an experience to be an experience.... The doing or making is artistic when the perceived result is of such a nature that its qualities as perceived have controlled the question of production. The act of producing that is directed by intent to produce something that is enjoyed in the immediate experience of perceiving has qualities that a spontaneous or uncontrolled activity does not have. (Dewey, 1934, p. 48)

Here, Dewey implies that art is a fusion of simultaneous cause and effect interactions between energies and participants. For our purposes in employing TAR, we see this fusion as a creative act. Creativity in this context is an organized, structured, and safe (for the participants) act that stimulates the content with the imagination of the 
participants. This vehicle (TAR) for delivering content, its comprehension and implications, is somewhat different from other forms of content delivery. How can we as instructors engage in provocative teaching along with established transmission models of delivering content?

The TAR concept was originated by Meyer (1998) as a professional development protocol for in-service school administrators. At the time, in the field of educational administration, there was no such use of such a drama-theatre application. Since then, a number of drama-theatre adaptations have evolved. TAR has also morphed, so-to-speak, into other variations by the author (Meyer, 2008; 2004; 2001a; 2001b; Meyer \& Mitchell, 2011), which presently seems more like cross-pollination between readers' theatre and process drama.

TAR is similar to readers' theatre in that participants gather to read a text live with some theatricality, though theatricality is not required unless staged (McCaslin, 2000). Through process drama, participants understand more about human behavior and their individual and collective understandings of the world they live in (as implied in O’Neill \& Lambert, 1982/1993, p.13). Using theatre in a community sense, the classroom becomes a venue to further awareness on a specific social or health issue (Nisker, Martin, Bluhm, \& Darr, 2006) and, to a certain extent role-playing permits learning in the sense of "acquiring new information and...raising awareness" (Bolton \& Heathcote, 1999, p. 9).

Thus, the TAR vehicle in the communication of educational research to practitioners/students is a highly innovative exploration that, through their participation, encourages and develops creativity among adult learners. By placing research findings and theories within a scripted dramatic piece, participants can affectivity and cognitively engage in the exploration of chosen issues within the safety of a script.

In this paper, we employ a TAR application as an additional teaching tool or activity in its application within a Master of Education course entitled Administration of Inclusive Schools.

When TAR, in any of its incarnations, is used as a teaching tool, all students have the opportunity to take on character roles in the piece (as either actors or readers) and to be audience members. Each TAR incorporates fundamental aspects of legal, administrative, and organizational theory (e.g., sources and uses of power and micropolitics). Because each scenario is grounded in some combination of research and interview data (where possible), dialogue is based on real phraseology that helps to create the sense of verisimilitude necessary to immerse both participants and audience into the scenario. To some extent, a case could be made to place TAR within the realm of ethnotheatre:

Ethnotheatre employs the traditional craft and artistic techniques of theatre production to mount for an audience a live performance event of research participants' experiences and/or the researcher's interpretations of data...The goal is to investigate a particular facet of the human condition for purposes of adapting those observations and insights into a performance medium is to investigate a particular facet of the human condition for purposes (Saldaña, 2005, p.1) 
A TAR participant, either in the observer role or in the more active participant role, can aid in the evolution of praxis in schools. We participate and observe drama presentations every day of our lives (Goffman, 1959). The designed or programmed dramas are those experienced through the media: television, cinema, live theatre, and the like. The nonprogrammed dramas are those experienced in daily life at home, the workplace, or at other locales.

These non-programmed dramas are an important aspect of theatre as representation. Part of its raison d'être is for the observer to be empathetic with the aesthetic theatre experience itself. A familiarity with such presentational formats is critical for the success of this application. Whether conscious or unconscious, viewers inherently use judgmental and intellectual protocols. These protocols create a sense of security, permitting viewers to sit and pass judgment on the presentation without fear of personal reprisal or loss of face before another viewer, peer, or superior. Whether or not viewers are moved to make a true change in their personal beliefs (in view of the content of the presentation) is not open to scrutiny by anyone other than themselves. This freedom to form a self-designed impression is critical to the change process because it creates within the viewer this sense of empowerment.

Our scenario use is similar to Mienczakowski (see 1997, 1999) in that his research has used participants' life experiences to serve as content material in drama-like scenarios. His work is very much engrossed in drama as a professional development term within the medical community. Rossiter et al. (2008) researched a number of theatrebased health research evaluations/theatre applications and concluded that:

Theatre holds great promise in the world of education and health research translation. By engaging audiences on a cognitive and emotional level, and by using both verbal and non-verbal (or physical) forms of communication, theatre has the potential to enhance health care practitioners' understanding of the complex emotional, interpersonal and psychological dynamics that arise. (p. 145)

We concur with this belief and use our TAR scenario within the genre of educational administration, with the same motives and outcome prospects.

\section{Methodology and In-Class Use}

Data was collected from questionnaire responses provided by students enrolled in an M.Ed. graduate course entitled Administration of Inclusive Schools. All participants were also current in-service teachers. The focus of the questionnaire was to gain insight and data into the effectiveness of a TAR scenario in helping the participants further understand the complexity of the issues examined. The data collected highlights the degree of affective and cognitive engagement of participants, and the contribution of the affective domain to knowledge acquisition. Unlike other case studies employed in the course, this TAR scenario allowed the participants to assume a designated character role without the need to improvise, and to give the dialogue the sense of presence and immediacy which a flat text cannot convey. Once immersed in the role, participants are provided with a perspective, which may be different from the one they experienced as a practitioner, and this allows them to lay bare their assumptions about, and understanding of, legal issues and school governance. This is a highly creative endeavor on the part of 
individual participants within a collective group setting. The participants are presented with a three-dimensional exposition of inclusive leadership theories and contexts that cannot be easily duplicated by other texts and/or simulations. Along with the overt legal and school administration issues that arise in discussion, other covert issues such as race, gender, leadership modeling, decision-making, and their effect on political power brokering within a public school board also come to light.

This TAR scenario, entitled An Inclusive Education Dilemma, ${ }^{1}$ fully accentuates the responsibilities of teachers and administrators in an almost daily battle with parents of an adolescent child who has co-morbid $\mathrm{AD} / \mathrm{HD}$, as well as conduct disorder conditions since birth. This has been exacerbated by the onset of a mild case of multiple sclerosis.

In February 2011, during a course on leadership and inclusive communities, students prepared for a class by reading the scenario in advance, and participated by voluntarily taking on character roles and reading aloud the scenario in a readers' theatre forum. We were present during the class, and jointly led the post-reading discussion.

\section{The TAR Scenario: An Inclusive Education Dilemma}

GC: Guidance Counselor, Betty

VP: Vice-Principal, Neil

Mom: Mrs. Kassner

Dad: Mr. Kassner

SED: Special Education Consultant, Natalie

Setting: GC, VP, SED are in a small conference room awaiting Mom and Dad for a very volatile meeting with regards to their 13-year-old son Terry, who has co-morbid ADHD, as well as conduct disorder conditions since birth. This has been aggravated by a by a mild case of oncoming multiple sclerosis.

SED: I am not looking forward to this meeting with the Kassner family. They are getting more difficult by the meeting.

GC: Well, it's their fourth in less than two weeks.

VP: Oh, since you're counting, don't forget the... what...100 or so we've already had in the last 2 years since Terry came here.

SED: They are concerned parents who know their rights, are lawyers, and have many of the school board and Department of Social Services on their side. We are a progressive school board, you know (sarcastically).

VP: Only one or two-Progressive is one thing, but insane is another. We're lucky after Terry broke Tommy McKay’s arm 2 weeks ago, that his parents haven’t sued us yet.

GC: "Yet" is the operative word. We were just plain lucky that Bill was there in the cafeteria on his toes when Terry "accidently" pushed Tommy in the food line. 
SED: What were they arguing over?

VP: Apparently, Terry has very strong views on how much ketchup should be used on or on the side with French fries.

SED: Oh c'mon- Should I ask how it started? We know how it ended.

VP: Well it seems as though they were going through the line, Tommy asked the server politely to put his ketchup on the side,-Terry screamed at the server that ketchup can only go on top of the fries-the server politely informed Terry that the choice of where the ketchup can be put was Tommy’s. "Not so," screamed back Terry, "It can only go on top!” Well his ADHD went into hyperdrive-if you excuse the metaphor-and he went into a rage pushing, screaming, and shoving Tommy- Tommy's tray fell-the floor got very slippery-and a minute later- Tommy is on the floor with a broken arm. Bill raced over at the first scream to try to control Terry but not before Tommy slipped on the floor.

SED: These almost daily outbursts are really upsetting everyone-especially his classmates and teachers. I'm at a loss.... Here come his parents.

\{Mr. and Mrs. Kassner enter the room- ready to battle\}

VP: Mr. and Mrs. Kassner-welcome, please be seated.

Dad: I hope you didn't call us in again discuss transferring Terry to another school because you know our response.

VP: Yes, I know, but the last several weeks have been impossible for all. And the School Board Superintendent's office has been informed that if we do not do something regarding Terry's presence in the school, there will be a major petition coming from parents-, which will lead into a legal action against the Board.

Dad: That will be nothing compared to the lawsuit I will bring against the Board if he's put out!

SED: Listen-nobody wants this to go to litigation Mr. Kassner. However, even with all the accommodations, we have put into place Terry is not advancing and his classmates are not either. The parents of those students have as much right for their children to learn as Terry does.

Mom: We have been through this for the past 10 years. All accommodations have been successful in the past. And now with the onset of MS, you need to have a more patience here and that is the issue.

GC: Mrs. Kassner, I've been working with Terry and his teacher team for 3 years here at school...his condition is deteriorating.

Dad: This we know...

GC: We have made accommodations of every type from preferential seating to PEBS, daily report cards, agenda books, Individual program plans for many courses, in servicing for faculty and support staff... 
Dad: Yes, we know all that but it is the law as you know-Charter of Rights and Freedoms section 15 paragraph $1 \ldots$

GC: Let me go on please. Terry has not improved either academically and behaviorally.

Mom: that is simply not true-At home-he has shown incredible improvement-both his Psychologist and Occupational Therapist have reported amazing progress in his interpersonal behaviors-We've given you the reports.

SED: Yes, you have and we've studied them-however, nothing in those reports reflects his life here at school_only at home or at the office of the Psychologist and Occupational therapist. Terry does not interact civilly with anyone here at school. And it is not as if either the Faculty members or his classmates haven't tried. As required, everyday there are reports filed explaining or describing Terry's actions. We have shown these to you. It is beyond our capacity to adequately deal with him anymore.

Dad: You know that is not enough. Our son's rights must be recognized and be provided for. He must be in an environment with his peers and not sent away to some institution for the handicapped. Your own PSP [Public school programs] program states that. So clearly, you are not doing enough. Sections 26 and 38 of the Education Act explicitly state that your teachers are responsible for delivering that education. You have resources to cover these expenses.

VP: That is true. But, $90 \%$ of our allocated resources are going towards Terry. We also have almost 400 other students in this school who need assistance as well.

Mom: They are not our concern.

VP: But they are ours. Many of those students' parents are claiming discrimination in that their children are not getting even remotely what Terry is gettingmany of them seem to believe it is unjust... action.

Mom: Again, that is not our concern-if they feel that way, they can bring legal

As I have said before-Terry is making progress...

GC: No, he is not-He has become more aggressive; he cannot cope with either the minimal amount of supervised and individual program requirements we offer him; he is unable to understand others' welfare; he has no remorse or guilt, especially after he verbally or physically abuses a classmate or teacher...

Mom: DO NOT ACCUSE OUR SON OF BEING A JUVENILE DELINQUENT!!!! He has legitimate and medically assessed issues...

SED: Yes, he does; however, that does not excuse him totally of viewing others as a threat, or lashing out at his classmates without provocation. He has little or no emotional control most of the time. He is also going through puberty and this is aggravating his behavior. He is getting further and further from following any form of order. His aggression is brought on fear to his classmates, especially the girls. It may only 
be a matter of time before one of the bigger boys will lose it and strike him in selfdefense.

Mom: Then you'll have to provide more supervision.

GC: There are no more personnel available or any other resources. He is not going to improve. As you know the Board will provide funding and transportation to an approved alternative institution.

Mom: That is not going to happen. This Board has an inclusion policy along with the Provincial Special Education Policy. You must fulfill those legal obligations under penalty of law.

VP: Mr. and Mrs. Kassner, there is a petition under way that will be brought forth at the next School Board meeting from over 100 parents of this school claiming that their children's right to a safe and complete education is in jeopardy due to your son's condition. The Board cannot simply dismiss it.

Mom: They will not be able to dismiss us either. You are legally responsible-we don't care about any petition-you must do the morally and legally responsible thing.

SED: We are doing that—but we have reached our limits.

Mom: There are no moral limits!

VP: Well, perhaps we have reached ours.

\section{Post-Reading Discussion and Data Collection}

The discussion that followed the reading of the scenario as well as the data collection was grounded in light of the stated goals of this master's level course; in particular, the following two served as the theoretical foundation of this scenario's use in this exercise:

- Recognize the constituent aspects of inclusive schooling (all children deserve an education appropriate to their individual learning needs and styles; all aspects of schooling, including leadership, should be inclusive); and

- appreciate the complexities associated with creating and administering an inclusive school (creating a school that is truly inclusive takes time and effort, as well as resources; in many cases, it also requires a shift in culture, as well as a leader who believes and espouses the value of such a philosophical approach; it also requires having staff "buy into" the approach).

The class consisted of 17 ( 3 males and 14 females) students with 15 written responses provided.

We created an anecdotal, 11-question survey that we distributed immediately after the reading of the scenario. This was done so as not to prejudicially influence the responses of the participants' vis-à-vis the classroom discussion. The questions were as follows:

1. After having been involved in a TAR scenario, what were your first impressions? 
2. Explain or describe how the TAR event enhanced your learning experience.

3. Describe or explain, from your observations of this TAR event, how successful the interaction between the players and characters were with course objectives.

4. If you participated in a role, what were your feelings regarding the role as you presented it?

5. How did this TAR piece and your participation in it (either as participant or observer-listener) enhance your understanding of the educational subject at hand (e.g. administration, inclusion, other).

6. Was the reality of this scenario's content successful in portraying the reality of the course content?

7. How was your understanding different between the silent reading of the scenario and the actual presentation of the scenario with live voices?

8. Do you believe the TAR scenario relates to the objectives of this course? Explain.

9. Does the use of TAR enhance the teaching of issues surrounding the administration of inclusive schools? Explain.

10. Is TAR a pedagogical/teaching tool that you would recommend employing in this course? Why or why not?

\section{Other comments}

\section{Discussion and Analysis of Selected Responses}

For the purposes of this paper, we have selected the following five questions for detailed response and analysis. Our analysis is based on a fusion of both questionnaire responses (all responses have been designated through bullets) and the authors' classroom observations of class members during the post-presentation reading of the scenario.

\section{first impressions?}

Question 1: After having been involved in a TAR scenario, what were your

Student responses. There were three general responses. First, there were responses that indicated the scenario represented much frustration for all parties. Typical was:

My first impression is that of frustration. Both parties are fighting for the rights of students in a sense. Parents wanting their child to get a proper and fair education; the staff frustrated at having tried everything, including that Terry is not managing in the school. This drama leaves you feeling deflated as a teacher (possibly as a parent as well). It is a realistic and common situation. (Student response, questionnaire, January 24, 2011)

Second, there were responses that painted the staff in a negative light to some degree: 
School staff was negative, acting unprofessionally when discussing the student. I questioned what supports were actually in place to meet the needs of the student. The staff appeared to be threatened by the parents...parents were also unwilling to change their views. (Student response, questionnaire, January 24, 2011)

And, "Unprofessionalism on the part of staff...schools are responsible for the needs of all students which is what the staff is trying to do" (Student response, questionnaire, January 24, 2011).

Third, there were also responses that indicated that this type of situation never has a clear winner:

A difficult case with lots of grey areas. Both sides have legitimate issues and seem to have developed hostility towards each other, the parents have laws and policy on their side; the school has the concerns of the other students...very difficult to determine a situation suitable for both parties. (Student response, questionnaire, January 24, 2011)

Analysis. After the questionnaire responses were collected, the ensuing class discussion seemed to favour more the frustration part that was demonstrated within all parties than the negativity of the portrayed teachers. From our observations of class participants, during the post-presentation, "frustration" as an abstract idea, indicates that no characters in the scenario were leaning towards any form of negotiation for a resolution. There were a number of beliefs that the school authorities were acting in an unprofessional manner, yet a counter conversation among some participants suggested that the school authorities were past the point of negotiation with the parents, because all interventions had been pursued. The moral debate within the class of - who is right and who is wrong - was unresolved and led to a further conversation regarding the social justice responsibilities of school personnel to those students with behavioural challenges.

\section{Question 6: Was the reality of this scenario's content successful in portraying the reality of the course content?}

\section{Student responses.}

"Yes and no-the school personnel and parents in my opinion were far too hostile."

"Someone in the room [should] be able to diffuse the situation."

"The scenario was very realistic and true to life."

"Yes, I believe so." (Student responses, questionnaire, January 24, 2011)

Analysis. The response was that the scenario was overwhelmingly realistic, even to those who believed that some members of the staff were acting in an unprofessional manner. Discussion conversations indicated that many of the class participants, whether teachers or administrators, had either participated, witnessed, or heard accounts from other school personnel that resembled the contents of the scenario and that the communication manner was very close, if not completely, accurate. 
Question 8: Do you believe the TAR scenario relates to the objectives of this course? Explain.

\section{Student responses.}

"Yes...in the dramatic form, this makes these more memorable."

"Yes, the use of role-play allows for the inclusion of all learning styles."

Yes. The objectives of the course seem to be expose us to practices used in inclusive schools. The TAR represented a very real situation to which it was interesting to try and apply some of those practices.

"Certainly the scenario brought to light the issues around inclusion (attitudes and arguments)."

"Yes...it helped me to better understand the role of the school professionals as well as the emotions of all involved in working to promote inclusion."

"Yes it gives context to the teaching situations and leadership that are current in our schools."

"Yes, it encouraged us to "put ourselves in the shoes" of an actual scenario, including the emotions involved in situations such as the one presented."

Yes, because it would provide realistic examples, although perhaps fictional...that would serve to improve participants' understanding and appreciation for the particular situation. "Real" or authentic scenarios provide a great starting point which will spark discussions among participants. (Student responses, questionnaire, January 24, 2011)

Analysis. The responses to this question are mostly geared to the above stated specific goals of the course, which focus on the recognition of the constituent aspects of inclusive schooling and the appreciation of the complexities associated with creating and administering an inclusive school.

Even though, as indicated in Question 1, some class participants were frustrated with a perceived lack of professionalism (from the live discussion) there was unanimous agreement that the TAR scenario brought to life both the administrative concerns, and that inclusive educational learning needs are not as easy to fulfil as one would hope. There are both offensive parents and defensive school personnel posturing for decisionmaking position. School culture and climate parameters were also more clearly brought into question. Issues of whether or not there should be complete buy-in to actual inclusive education policies, and how this might be accomplished, were evident. These course awareness goals were very successful in both on-paper responses and class discussions.

Question 9: Does the use of TAR enhance the teaching of issues surrounding the administration of inclusive schools? Explain.

\section{Student responses.}


"I think that the use of TAR enhanced the learning experience. It helped make the situation of working to support learning challenged students more real. It was also effective to provide a starting point for discussion of difficult topics."

"TAR certainly raises questions on [how one] responds professionally and properly."

"Yes, it allows for expression and emotions to be reflected and conveyed. Inclusion/exclusion education often involves emotional concerns."

"Yes, as this issue is occurring in schools and we were able to discuss administrative issues."

"[It] gives added perspectives and contexts to a case study situation."

"Yes, through the group discussions (afterwards) this TAR represented a very real situation to which it was interesting to try and apply some of those practices."

"TAR can certainly raise questions about how to better our handling of inclusion" (Student responses, questionnaire, January 24, 2011).

Analysis. All responses were positive in supporting a TAR application as a teaching tool. As the responses indicated, a TAR employment was most useful in provoking class discussion on difficult inclusion issues and can challenge (or support) professional behaviour in such instances. As mentioned earlier, much debate occurred on the manner in which the school personnel communicated with the parents in terms of professionalism. This led to a more detailed discussion of describing the components of the most appropriate ways of communication. The scenario's use as a case study led to additional comments regarding the authenticity of its content, and not necessarily in the working dialog. This led to additional discussions in the following areas: the difference between the real vs. perceived definitions of inclusion, exclusion, and defining the actual inclusionary practise within schools.

Question 10: Is TAR a pedagogical/teaching tool that you would recommend employing in this course? Why or why not?

\section{Student responses.}

"Yes, TAR is a very useful and effective teaching tool...it presents important ideas for consideration in a format that is engaging and nove.l"

"Yes, it gives a common perspective and makes a challenging topic real."

"Yes - I would say that this type of scenario could be a class opener for topic discussions to support chapter readings...perhaps even part of presentation assessment."

"Yes - because the scenarios allow for authentic and meaningful discussions."

"Yes, along with other pedagogical/teaching tools, it ensures that differentiated instruction is happening." 
"Yes, it added engagement, context and insights [into real life scenarios]."

"Yes, it leads to a large group discussion with special consideration to the various roles in a true-to-life scenario" (Student responses, questionnaire, January 24, 2011).

Analysis. The above student responses were typically positive responses, which implied that TAR, used as a teaching tool, provided a successful learning experience for class participants, and that it should be employed as a vehicle in an M.Ed. class. One respondent also said that it should be used sparingly in the sense that TAR scenarios should be employed to assist in "critical" content areas that would emphasize legal or psychological issues such as legislated/mandated implementation and resource allotment - especially those of teacher assistants in the classroom. Other areas mentioned for using TAR scenarios were in classroom management; teacher-to-student contact time (and its allocation among student or student groupings); legal responsibilities and obligations for reporting; and student behaviour codes of conduct, discipline standards, and teacher or administrator reaction protocols.

\section{Towards a Convergence of Theory, Practice, and Knowledge}

Greene (1995) challenges us to seek the use of imagination within our preservice teacher preparation, and by extension, administrator preparation programs.

It is difficult for me to teach educational history or philosophy to teachers-to-be without engaging them in the domain of imagination and metaphor. How else are they to make meaning out of the discrepant things they learn? How else are they to see themselves as practitioners, working to choose, working to teaching an often indecipherable world? (p. 99)

The use of imagination and metaphor are foundational infrastructure girders in teaching pedagogy. But more often than not, our M.Ed. students (in-service teachers) have seen their imagination and understanding of metaphor in creative adventures somewhat stifled (if not put into stasis) with their undergraduate and working experiences. The response of these M.Ed. students indicates that the engagement of a TAR scenario within an educational administration course is almost alien to them. The responses in action, on paper, and in post-scenario discussion groups successfully demonstrated that a creative approach to data or in this case, inclusive education content expanded the students understanding and expansion of knowledge and its possible application. The use of theatre, in a non-confrontational TAR setting, linked the content with its interpretation (through class discussion) within praxis of a classroom. This pedagogical approach proved successful in bringing together content issues with course objectives. Barone (1991/2000), in a discussion on Norman Mailer, suggests two "signposts on the road to pedagogical...maturity" (p. 67).

The first... [w]hen we arrange the learning environment and select the activities in which we recommend that students engage, we are not performing a merely technical exercise. The humanities, the arts, the sciences...none of these areas of study are comprised of value-neutral content or thinking skills to be acquired by students in a moral vacuum...the second...pay attention to history. (p. 67) 
Much of our teaching is theoretical, abstract, and prescriptive. The dissemination of data and knowledge about legislation, guidelines, and the like tend to be rushed, superficial and many times somewhat disconnected from practice. Barone (1991/2000) suggests here that content is not "value-neutral" and that the choices that will be made by teachers will always have ethical ramifications to all involved constituents. History is also a great teacher in itself. Using TAR scenarios based or inspired by actual events bring a reality to the teaching pedagogy, which by its nature as a piece of art, forces a value-laden or moral stand on the part of the participant. It fits very well into the constructivist pedagogical framework (see Fosnot, 1996; Von Glaserfield, 1996; Wertsch, 1990) because the onus of the learning experience falls more squarely on the learner than the instructor.

In effect, the TAR scenario is what Latta (2001) would refer to as "aesthetic play" (p. 100). In this classroom, in-service teachers "make sense" of their world (their eventual teaching environment) by interfacing with a scenario of literary non-fiction that challenges any presupposed perceptions of value and moral interpersonal relationships. Their participatory experience evokes a new emotional response and transforms it into a new relationship (Dewey, 1934, p. 79) of the event (or data) and themselves.

The convergence of theory, practice, and knowledge in using a TAR scenario demonstrates its benefit as teaching tool. Both the student and the instructor deconstruct the work to reconstruct value and moral endgames. These endgames, consequences of data results, ad hoc surveys, or simple discussions fuse art with reality and force an emotional, perhaps pedagogical, learning dilemma for the student (in this case in-service teacher) to resolve within a praxis orientation. Here, perhaps, the TAR scenario, "evokes sensibilities that are otherwise masked” (Edelman, 1995, p. 53) from other genres because the student participants become more than a two-dimensional observer; rather, they become corporeal voyeurs with a moral prerogative. ${ }^{2}$ 


\section{References}

Barone, T. (2000). Ambiguity and the curriculum: Lessons from the literary nonfiction of Norman Mailer. In T. Barone (Ed.), Aesthetics, politics, and educational inquiry: Essays and examples (pp. 61-70). New York, NY: Peter Lang. (Original work published in 1991)

Bolton, G., \& Heathcote, D. (1999). So you want to use role-play? A new approach in how to plan. London, UK: Trentham Books.

Dewey, J. (1934). Art as experience. New York, NY: Perigee Books.

Edelman, M. (1995). From art to politics: How artistic creations shape political conceptions. Chicago, IL: University of Chicago Press.

Fosnot, C. (1996) (Ed.). Constructivism: Theory, perspectives, and practice. New York, NY: Teachers College Press.

Goffman, E. (1959). The presentation of self in everyday life. New York,

Greene, M. (1995). Releasing the imagination: Essays on education, the arts, and social change. San Francisco, CA: Jossey-Bass

Latta, M. (2001). The possibilities of play in the classroom. New York, NY: Peter Lang.

McCaslin, N. (2000). Creative drama in the classroom and beyond. New York: Longman.

Meyer, M.J. (1998). Transitional wars: A study of power, control, and conflict in executive succession-Theatre As Representation . Unpublished Doctoral Dissertation, McGill University, Montreal, Canada.

Meyer, M.J. (2001a). Reflective leadership training in practice using theatre as representation. International Journal of Leadership in Education, 4(2), 149-169.

Meyer, M. J. (2001b). Illustrating issues of power and control: The use of a dramatic scenario in administration training. Educational Management and Administration, 29(4), 449-465.

Meyer, M.J. (2004).Theatre as representation (TAR) in the teaching of teacher and administrator preparation programs. International Electronic Journal for Leadership in Learning, 8(6). Retrieved from http://www.ucalgary.ca/ iejll.

Meyer, M.J. (2008). Improving the selection and performance of school principals: Using theatre as a professional development tool. Lewiston, NY: The Edwin Mellon Press.

Meyer, M.J., \& Macmillan, R.B. (2002). Enlivening data: Using theatre to communicate educational research. Paper presented at the American Educational Research Association Annual Conference at New Orleans, LA.

Meyer, M. J., \& Mitchell, C. (2011). Contested practices of social justice. Journal of Educational Administration and Foundations, 21(1), 1-22. 
Mienczakowski. J. (1997). Theatre of change. Research in Drama Education, 2(2), 159172.

Mienczakowski. J. (1999). Ethnography in the hands of participants: Tools of dramatic discovery. Studies in Ethnography, 28, 145-161.

Nisker, J., Martin, D., Bluhm, R., \& Darr, A. (2006).Theatre as a public engagement tool for health-policy development. Health Policy, 78, 258-271. Retrieved from http://dx.doi.org/10.1016/j.healthpol.2005.10.009

O’Neil, C., \& Lambert, A. (1993). Drama structures: A practical handbook for teachers. Portsmouth, NH: Heineman. (Original work published 1982)

Rossiter, K., Kontos, P., Colantio, A., Gilbert, J., Gray,J., \& Keightley, M. (2008). Staging drama: Theatre as a tool for analysis and knowledge transfer in health research. Social Science \& Medicine, 66, 130-146.

Saldaña, J. (2005). Ethnodrama: An anthology of reality theatre. Walnut Creek, CA: Altamira Press.

Von Glaserfeld, E. (1996). Introduction: Aspects of constructivism. In C. Fosnot (Ed.), Constructivism: Theory, perspectives and practice (pp. 3-7). New York, NY: Teachers College Press.

Wertsch, J.V. (1990). The voice of rationality in a sociocultural approach to mind. In L.C. Moll (Ed.), Vygotsky and education: Instructional implications and applications of sociohistorical psychology (pp. 111-126). New York, NY: Cambridge University Press.

\section{Endnotes}

${ }^{1}$ This scenario was written by Matthew J. Meyer in December 2010 and was vetted by a clinical educational psychologist for medical and clinical accuracy. Its content is based primarily on conversations and classroom discussions with, at the time, current in-service teachers and administrators.

${ }^{2}$ For a detailed description and TAR scenario creation and writing protocol see Meyer (2008) and Meyer and Macmillan (2002). 